\section{Postharvest Spoilage Incidence and Prestorage Treatment in Chinese Chestnut and Complex Hybrid Cultivars}

\author{
J. Bryan Webber ${ }^{1}$, Darcy Gordon ${ }^{1}$, Adolfo Rosati ${ }^{2}$, \\ Nicholas Meier ${ }^{1}$, Michael Gold ${ }^{1}$, and Ronald Revord ${ }^{1}$
}

AdDitional INDEX wORDs. Castanea mollissima, cold storage, postharvest quality, pre-treatment, screening, storage molds

Summary. U.S. chestnut (Castanea sp.) production is expanding as knowledge of seedling cultivation and germplasm advances. Chestnuts have high starch and water content, making them highly perishable; therefore, they require cold storage immediately following harvest. Postharvest spoilage remains a significant area for improvement. Several postharvest fungi (including Fusarium sp. and Penicillium sp.) can infect chestnuts during storage, leading to spoilage and nonsellable nuts. The annual crop losses can reach up to $10 \%$, thereby affecting trees differently. Our research objectives were to 1 ) evaluate spoilage incidence on the interior (i.e., pellicle, kernel) and exterior (i.e., nutshell) of the nut over the course of 200 days of cold storage on eight cultivars and 2) assess the impact of food contact-approved chlorine solution and $2 \%$ peracetic acid (PAA) with $27 \%$ hydrogen peroxide prestorage treatments for spoilage suppression on 'Qing' nuts. Fourteen timepoints were observed during the study period, each with four replications of 16 nuts. An additional four replicates of 16 'Qing' nuts were treated prestorage and observed over seven time points. The incidence of spoilage was reported as the percentage of nonsellable nuts for each treatment and cultivar at four timepoints. The nut interior showed the highest spoilage incidence after 200 days, with four cultivars having $>30 \%$ nonsellable nuts. Overall, the cultivars had an average of $10 \%$ nonsellable nuts from interior spoilage after 60 days in storage. 'Hong Kong' had the highest percentage of nonsellable nuts by the end of the study at $60 \%$, whereas 'Qing' and 'Mossbarger' had the lowest rates, with only $14 \%$ nonsellable nuts. Spoilage of the exterior, although less frequent, is visible to buyers and impacts nut marketability. 'Kohr' had the highest percentage of nonsellable nuts because of exterior spoilage (35.9\%). 'Mossbarger' had the lowest percentage of nonsellable nuts because of exterior spoilage (3.1\%). 'Qing' nuts treated with 500 ppm chlorine and $100 / 200$ ppm PAA demonstrated reduced exterior spoilage with longer storage times. Prestorage treatment did not show efficacy for reducing interior spoilage. This study provides a preliminary report of evidence that cultivar differences influence the spoilage incidence and supports taking nuts to market within 60 days of harvesting. These preliminary data also inform breeding parent combinations and studies of inheritance for postharvest spoilage tolerance at the University of Missouri Center for Agroforestry breeding program.

$\mathrm{U}$ nited States chestnut (Castanea sp.) production is expanding rapidly as growers recognize chestnuts as a high-value, low-input

Received for publication 29 Oct. 2021. Accepted for publication 10 Dec. 2021

Published online 8 February 2022

${ }^{1}$ University of Missouri Center for Agroforestry, Anheuser-Busch Natural Resources Building, 1111 Rollins Street, Columbia, MO 65201

${ }^{2}$ Italy Council for Agricultural Research and Economics, Research Centre for Olive, Fruit and Citrus Crops, Via Nursina 2, 06049 Spoleto (PG), Italy

R.R. is the corresponding author E-mail: r.revord@ missouri.edu.

This is an open access article distributed under the CC BY-NC-ND license (https://creativecommons. org/licenses/by-nc-nd/4.0/).

https://doi.org/10.21273/HORTTECH04981-21 tree crop that offers small farmers an option for diversification (Aguilar et al., 2009). The number of chestnut farms in the eastern and midwestern United States grew by $57 \%$ between 2012 and 2017, and several hundreds of orchards have entered mature bearing years since that time (U.S. Department of Agriculture, National Agriculture Statistics Service, 2018). Chestnuts can be sold at prices ranging from $\$ 3.40 / \mathrm{lb}$ (wholesale) to $\$ 7 / \mathrm{lb}$ if marketed direct to consumer (Cai and Gold, 2021). The primary chestnut market occurs during the holidays (for example, Christmas) that occur 2 months following harvest (Hochmuth et al., 2018). The genus Castanea contains eight species that may hybridize: allegheny chinquapin (C. pumila); american chestnut (C. dentata); chinese chestnut (C. mollissima); chinese chinquapin (C. henryi); european chestnut (C. sativa); japanese chestnut (Castanea creneta); ozark chinquapin (C. ozarkensis); and seguin chestnut (C. seguinii). Each chestnut species and their hybrids produce edible nuts; however, japanese chestnut, european chestnut, chinese chestnut, and interspecific and complex hybrids produce large, sweet nuts that are particularly suited for commercial production (Revord et al., 2021). Chinese chestnut and complex hybrids are well-adapted for the temperate growing environment found in the midwestern and eastern United States because of their disease resistance and cold hardiness (Gold et al., 2006; Hunt et al., 2012; Revord et al., 2021).

Unlike most other tree nuts, which are typically oily, high in protein, and can be safely stored at room temperature, chestnuts have much higher starch and moisture contents ( $40 \%$ to $60 \%$ water), thereby making the nuts highly perishable and susceptible to spoilage (Ertan et al., 2015). Chestnuts require cold storage between 0 and $4{ }^{\circ} \mathrm{C}$ immediately after harvest to remain fresh for a highvalue market (Hunt et al., 2012). Several postharvest fungi, including Fusarium and Penicillium species, as

\begin{tabular}{llll}
\hline $\begin{array}{l}\text { Units } \\
\text { To convert U.S. to SI, } \\
\text { multiply by }\end{array}$ & U.S. unit & SI unit & $\begin{array}{l}\text { To convert SI to U.S., } \\
\text { multiply by }\end{array}$ \\
\hline 0.3048 & $\mathrm{ft}$ & $\mathrm{m}$ & 3.2808 \\
3.7854 & $\mathrm{gal}$ & $\mathrm{L}$ & 0.2642 \\
2.54 & inch $(\mathrm{es})$ & $\mathrm{cm}$ & 0.3937 \\
6.4516 & inch $^{2}$ & $\mathrm{~cm}^{2}$ & 0.1550 \\
28.3495 & $\mathrm{Oz}$ & $\mathrm{g}$ & 0.0353 \\
0.001 & $\mathrm{ppm}$ & $\mathrm{g} \cdot \mathrm{L}^{-1}$ & 1000 \\
0.9464 & $\mathrm{qt}$ & $\mathrm{L}$ & 1.0567 \\
$\left({ }^{\circ} \mathrm{F}-32\right) \div 1.8$ & ${ }^{\circ} \mathrm{F}$ & ${ }^{\circ} \mathrm{C}$ & $\left({ }^{\circ} \mathrm{C} \times 1.8\right)+32$ \\
& & &
\end{tabular}


well as an emerging fungal pathogen, Gnomoniopsis, can infect chestnuts, even with proper cold storage conditions (Kader, 2003; Lione et al., 2019; Tamietti, 2016; Visentin et al., 2012). Postharvest fungi cause spoilage that impacts the nut exterior (nutshell), interior (pellicle, kernel), or both, resulting in nonsellable nuts. The appearance of spoilage on the exterior of the shell influences the consumers' willingness to pay a premium for nuts. Spoilage also impacts the interior of the nuts, with no visible signs on the exterior (Mencarelli, 2001), which complicates quality control procedures, customer retention, and business scalability.

Research of postharvest procedures and best practices has sought to prolong the shelf life of chestnuts before they go to market. Sanitation at the time of harvest can have an impact on postharvest nut quality. Nuts harvested from the ground have been shown to have higher levels of postharvest pathogens than nuts harvested directly from the tree (DonisGonzález et al., 2016). Procedures shown to lengthen chestnut storage life include water curing, high storage atmosphere carbon dioxide levels (Cecchini et al., 2011), pretreatment fumigations (with carbon sulfide, phosphine, or methyl bromide), irradiation with gamma rays or electron beam drying methods, gaseous ozone treatments, or the addition of biological products during water curing (Delgado et al., 2016, 2017; Ruocco et al., 2016; Vettraino et al., 2020). Many of these postharvest treatment methods require large commercialscale operations that have the infrastructure for large, heated water baths or the application of hazardous chemicals. Small-scale growers often create makeshift cold storage systems by constructing a highly insulated room with an air conditioning unit to store their crop between harvest and selling the nuts. Even with proper cold storage, growers note annual crop losses that reach up to $10 \%$, thereby affecting individual trees differently (Ekman, 2014). Postharvest chestnut spoilage remains a significant area for improvement with little to no research, including the response of multiple chestnut cultivars under long-term cold storage. Furthermore, few studies have incorporated food-safe household or retail products as prestorage treatment options for smallscale operations.

In this preliminary study, nuts from the chestnut germplasm repository from one growing season were used to l) evaluate eight chestnut cultivars for spoilage incidence on the nut interior (pellicle, kernel) and exterior (nutshell) at 14 timepoints over the course of $200 \mathrm{~d}$ of cold storage and 2) assess the impact of food contact-approved prestorage household chemical treatments for mold suppression on 'Qing' nuts.

\section{Materials and methods Cultivar storage study}

Plant material. Chestnuts were collected from the germplasm repository at the University of Missouri Horticulture and Agroforestry Research Center near New Franklin, MO (lat. $39^{\circ} 02^{\prime} \mathrm{N}$, long. $92^{\circ} 76^{\prime} \mathrm{W}$ ). The orchards were planted in 1998-99, at 30- × 30-ft spacing, on ridgetops with well-draining silt loam soil and comprised a collection of more than 50 unique chestnut cultivars (Revord et al., 2021). The average annual precipitation of the experimental site is 38 inches; trees were not irrigated. Seven chinese chestnut cultivars were included: Mossbarger, Gideon, AU Homestead, Hong Kong, Peach, Kohr, and Qing. One interspecific hybrid, 'Sleeping Giant' $(C$. mollissima $\times C$. crenata $\times C$. dentata , was included. These eight cultivars were chosen because they are considered among the most suitable for cultivation in Missouri based on a previous evaluation (Hunt et al., 2009, 2005).

Chestnut harvest. Chestnuts were hand-harvested from a frequently mown grassy orchard floor every 24 to $48 \mathrm{~h}$ over the course of several days. Harvested nuts were immediately stored in plastic bags in a cold room at $4{ }^{\circ} \mathrm{C}$. Nuts from two trees per cultivar were randomly selected, pooled, and sorted with a grading machine. Only nuts between 8 and $18 \mathrm{~g}$ were used in the experiment. Sorted chestnuts were soaked in clean, cool water for 5 min with gentle agitation to remove any dirt, and any floating nuts were discarded. Then, chestnuts were soaked for 10 min in a chlorine solution of $\approx 550$ ppm (1:100 dilution of chlorine solution with $5.25 \%$ sodium hypochlorite labeled for food contact) with gentle agitation. The $\mathrm{pH}$ of the solution was not monitored or adjusted. Then, nuts were spread thinly on metal screening to air-dry for $\mathrm{l} h$ or until no external moisture was visible on the shells. Working surfaces were disinfected using a $10 \%$ chlorine solution before spreading the chestnuts to dry. Handling and surface disinfection were followed by the initial sample evaluation ( time $=0$ ).

Cold STORAge SAMPLE BLOCK. Each nut was numbered with a marker before being packaged in groups of 16 nuts in microperforated, 1-qt, bioriented polypropylene bags (30 holes/inch ${ }^{2}$; PrismPak, Berwick, PA) and closed with twist ties. For each cultivar, four bags were prepared for each of 14 timepoints: 16 nuts/ bag $\times 4$ bags $\times 14$ timepoints $(896$ total nuts per cultivar).

The initial sample (time $=0$ ) was immediately evaluated using the procedures described in the following section, whereas the other bags were immediately placed in disinfected, lidded, solid plastic, 18-gal bins (Roughneck storage containers; Rubbermaid, Atlanta, GA) in a cold storage room. The bags of chestnuts were placed in plastic milk crates within the plastic bins and did not touch the bottom, sides, or lid of the bins. Sterile cloths at the bottom of the bins were kept wet (with $10 \%$ chlorine solution) to keep bin humidity as high as possible throughout the duration of the experiment. A digital thermometer-hygrometer was included in each bin to confirm that bin conditions were uniformly $4{ }^{\circ} \mathrm{C}$ with $99 \%$ relative humidity. The oxygen and carbon dioxide levels inside the bins were not measured or monitored.

Cold storage evaluations. For each cultivar, at each timepoint, the four replications were removed from the bin, destructively sampled, and evaluated. Each nut was evaluated for exterior shell mold based on a descriptive decay rating scale from 1 to 5 (Table 1 ). Then, each chestnut was sliced with a knife, and groups of 16 were heated together in a microwave oven on medium power for $60 \mathrm{~s}$ to loosen the pellicle. Then, the nuts were peeled. Then, the interior of each shell (pellicle and kernel) was scored based on the decay rating scale 
Table 1. Descriptive standards and ratings for evaluating chestnuts for exterior and interior spoilage to determine the marketability of the nuts (e.g., sellable or nonsellable).

\begin{tabular}{cl}
\hline Rating $^{\mathbf{z}}$ & \multicolumn{1}{c}{ Descriptive standards } \\
\hline 1 & Uniformly pristine, no signs of mold or decay visible to the naked eye \\
2 & Only tiny specks or areas of discoloration not noticeable to consumers \\
3 & Minor but clearly visible localized discoloration, mold, or decay \\
4 & Mold and discoloration evident on up to half of the surface \\
5 & Mold and discoloration evident on more than half of the surface \\
\hline
\end{tabular}

${ }_{\mathrm{z}} 1$ and $2=$ sellable nuts; 3,4 , and $5=$ nonsellable nuts.

of 1 to 5 . The percentage of nonsellable nuts was assessed for each of the cultivars using the spoilage decay rating scale. Nuts with a decay rating of 1 or 2 had levels of decay acceptable for marketing (sellable), whereas the nuts with decay ratings of 3,4 , or 5 were unacceptable for marketing (nonsellable) (Fig. 1).

For each cultivar, replications were evaluated every $14 \mathrm{~d}$ for the first $120 \mathrm{~d}$ of cold storage. Four additional observations occurred at longer intervals until $200 \mathrm{~d}$ in cold storage had been reached. Data grouped into four timepoints $(0,60,120$, and $200 \pm 7$ d) that highlight spoilage progression are presented as statistical analysis factors and recommendations.

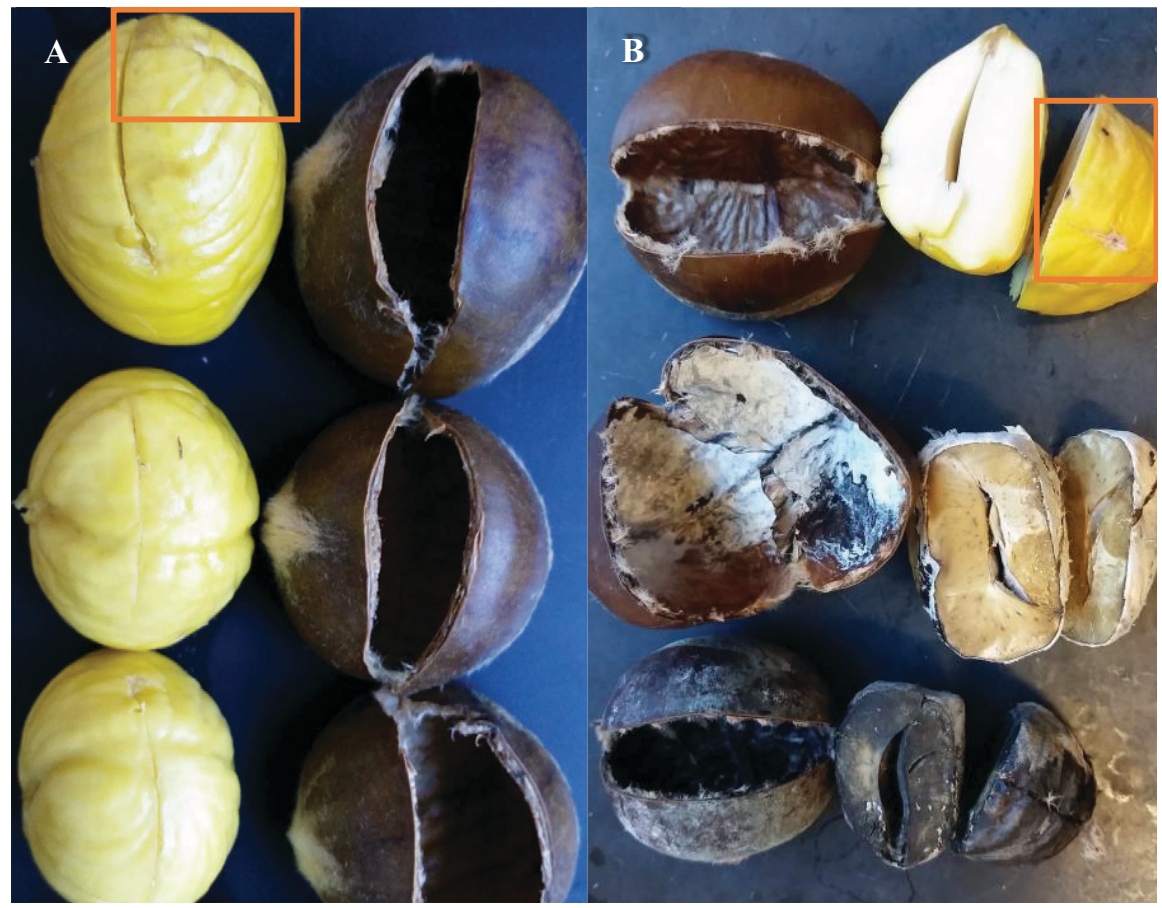

Fig. 1. Range of chestnut spoilage incidence showing ratings of 1 and 2 (sellable nuts) and ratings of 3 and 5 (nonsellable nuts) (Table 1). (A) Rating 1 (lower two nuts) indicates uniformly pristine nuts with no sign of mold or decay to the naked eye. Rating 2 (top nut) indicates tiny areas of discoloration not noticeable to the consumer. (B) Rating 3 (top nut) indicates minor but clearly visible localized spots of mold on the nut interior. Rating 5 (bottom two nuts) indicates mold and discoloration covering more than half of the surface on the interior and exterior. treatments, respectively. The chlorine and PAA treatments are approved for food contact and were applied in accordance with the product manufacturer's instructions. Nuts were divided into the five treatment groups: a) high chlorine (500 ppm), b) low chlorine (100 ppm), c) high PAA (200 ppm), d) low PAA (100 ppm), and e) water control.

Chestnuts were soaked in the treatment solution with gentle stirring for $10 \mathrm{~min}$ in the case of the chlorine treatments or $3 \mathrm{~min}$ in the case of PAA treatments. The water control was $10 \mathrm{~min}$. The high-chlorine treatment was the same as that used for the cultivar storage study; therefore, the same 'Qing' nuts were considered for both studies. After treatment, nuts were spread thinly on a metal grill to air-dry for $1 \mathrm{~h}$ or until external moisture was not visible on the shells. Finally, the nuts were packaged for storage in microperforated plastic bags. All bagged samples were stored in bins at $4^{\circ} \mathrm{C}$ with high humidity and evaluated as described previously.

Statistical anAlysis. Before analysis, the data were assessed for normality using the Shapiro-Wilks test. A one-way analysis of variance was performed for the mean percentage of nonsellable nuts because of interior or exterior spoilage at $0,60,120$, and 200 $\mathrm{d}$ of storage (Table 1). Pairwise post hoc analyses were conducted using Tukey's honestly significant difference $(\alpha=0.05)$ test to compare means among cultivars at $0,60,120$, and 200 $\mathrm{d}$ in storage. Statistical calculations were performed using the agricolae package (Mendiburu and Yaseen, 2020) in the R statistics environment (R Core Team, 2020; R Studio Team, 2020).

\section{Results and discussion Cultivar storage study}

At day 0 , exterior spoilage was not detectable among any of the cultivars (Fig. 2). Minor interior spoilage $(<10 \%$ average) incidence was recorded in six 
cultivars (Fig. 3). However, these differences were not statistically significant (Table 2). At $60 \mathrm{~d}$ under cold storage, 'Kohr' (10.9\%) and 'Peach' (9.4\%) had significantly higher percentages of nonsellable nuts than 'Hong Kong' $(0 \%)$ and 'Mossbarger' $(0 \%)$ based on exterior spoilage. Regarding interior spoilage, 'Hong Kong' (20.3\%) had the highest percentage of nonsellable nuts and 'Gideon' (3.1\%) had the lowest percentage of nonsellable nuts (Fig. 3).

At $120 \mathrm{~d}$ of cold storage, 'Kohr' $(26.6 \%)$ harbored significantly higher exterior spoilage than six other cultivars, with Hong Kong (1.6\%) and Mossbarger (3.1\%) having the lowest percentage of nonsellable nuts (Fig. 2). Regarding interior spoilage, 'Hong Kong' (39.1\%) had a significantly higher percentage of nonsellable nuts than six other cultivars. 'Kohr' (23.4\%) had the second highest percentage of nonsellable nuts, whereas 'Mossbarger'
(7.8\%), 'Peach' $(7.8 \%)$, and 'Qing' $(7.8 \%)$ had the lowest percentages of nonsellable nuts (Fig. 3).

At $200 \mathrm{~d}$ under cold storage, 'Kohr' (35.9\%) had the highest percentage of nonsellable nuts based on exterior spoilage, and this percentage was significantly higher than those of 'Qing' (7.8\%) and 'Mossbarger' (1.6\%) (Fig. 2). 'Gideon' (31.3\%) and 'Peach' (29.7\%) had the next highest percentages of nonsellable nuts, and those percentages were also significantly higher than that of 'Mossbarger'. Regarding interior ratings, 'Hong Kong' $(60.9 \%)$ had the highest percentage of nonsellable nuts, and this percentage was significantly higher than those of 'Gideon' (21.9\%), 'Peach' (23.4\%), 'Qing' (14.1\%), and 'Mossbarger' (9.4\%) (Fig. 3). 'Kohr' (46.9\%) had the next highest percentage of nonsellable nuts, and this percentage was significantly higher than those of 'Qing' (14.1\%), and 'Mossbarger' $(9.4 \%)$.

These results showed that 'Mossbarger' consistently had the lowest percentage of nonsellable nuts of all the cultivars for both the exterior and interior ratings at each evaluation timepoint. 'Kohr' consistently had the highest percentage of nonsellable nuts for the exterior ratings at each evaluation timepoint. Of all the cultivars, Hong Kong had one of the lowest percentages of nonsellable nuts based on the exterior ratings but the highest percentage of nonsellable nuts based on interior ratings. 'Hong Kong' is an example of how the quality of the exterior of the nuts does not always indicate the quality of the interior of the nuts.

This preliminary study provides evidence that there are significant differences among chestnut cultivars in their ability to maintain quality throughout long-term storage under
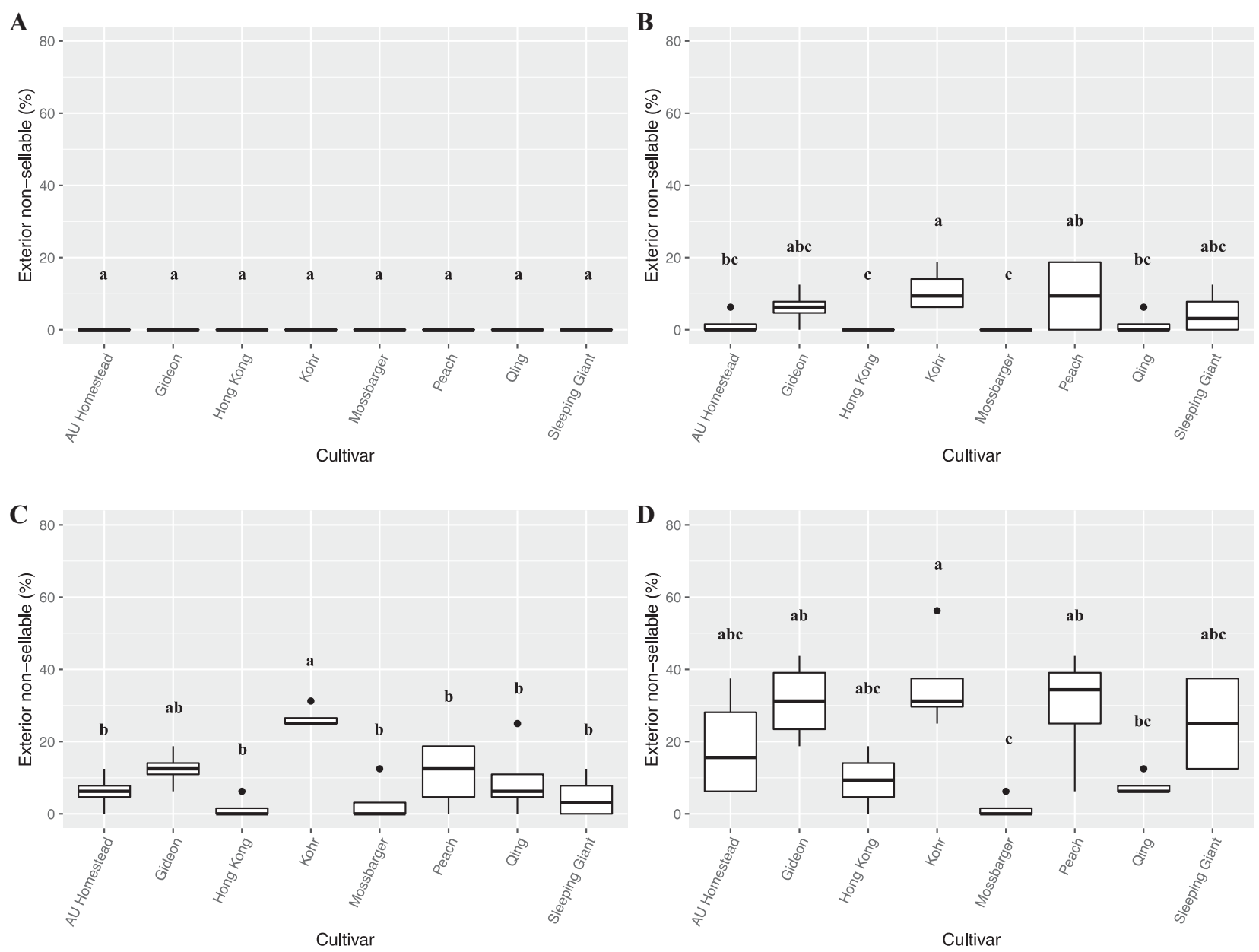

Fig. 2. Percentage of nonsellable chestnuts based on exterior spoilage at (A) $0 \mathrm{~d}$, (B) $60 \mathrm{~d}$, (C) $120 \mathrm{~d}$, and (D) $200 \mathrm{~d}$ postharvest. Values followed by different letters are significantly different according to Tukey's honestly significant different $(\alpha=0.05)$ test. 

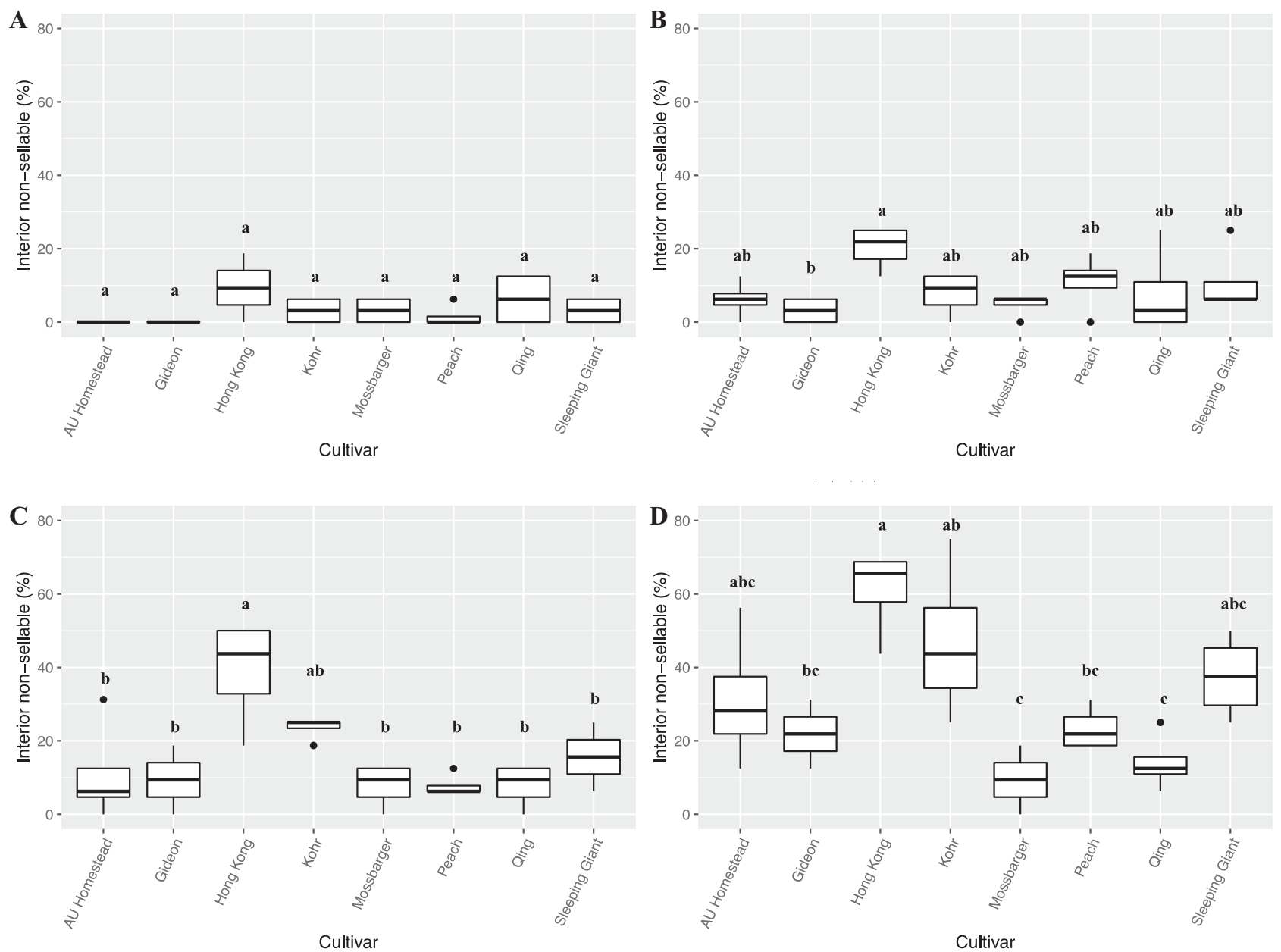

Fig. 3. Percentage of nonsellable chestnuts based on interior spoilage at (A) $0 \mathrm{~d}$, (B) $60 \mathrm{~d}$, (C) $120 \mathrm{~d}$, and (D) $200 \mathrm{~d}$ postharvest. Values followed by different letters are significantly different according to Tukey's honestly significant different $(\alpha=0.05)$ test.

the conditions presented here. There is evidence that 'Qing' and 'Mossbarger' resist external spoilage over the course of $200 \mathrm{~d}$ in cold storage, whereas 'Gideon', 'Kohr', 'Peach', and 'Sleeping Giant' are more susceptible to external spoilage over the course of $200 \mathrm{~d}$ in cold storage. There is also evidence that 'Qing', 'Mossbarger', and, to a degree, 'AU Homestead', 'Gideon', 'Peach', and 'Sleeping Giant' may resist internal spoilage over the course of $200 \mathrm{~d}$ in cold storage. Results may vary with different growing years, environments, cultivar ramets, and other noncultivar-related variables.
Further research is needed for a wider range of applications.

The evidence gathered here and evidence in the previous literature suggest that selling nuts of all cultivars soon after harvest is optimal because that is when nuts are at peak freshness and loss to postharvest spoilage can be

Table 2. Results of the one-way analysis of variance of the percentage of nonsellable chestnuts based on exterior and interior spoilage ratings using the response variable "cultivar" at each evaluation timepoint postharvest.

\begin{tabular}{lccccr}
\hline Time after storage $(\mathbf{d})$ & df & Sum of squares & Mean square & $F$ & $P>F$ \\
\hline Exterior rating & & & & & \\
0 & 7 & 0 & 0 & $\mathrm{~N} / \mathrm{A}^{\mathrm{z}}$ & $\mathrm{N} / \mathrm{A}$ \\
60 & 7 & 502.9 & 71.8 & 2.4 & 0.04 \\
120 & 7 & 1758.0 & 251.1 & 5.7 & $<0.01$ \\
200 & 7 & 4409.0 & 629.9 & 4.5 & $<0.01$ \\
Interior rating & & & 40.2 & & \\
0 & 7 & 282.0 & 113.7 & 2.9 & 0.10 \\
60 & 7 & 795.9 & 487.6 & 6.1 & $<0.04$ \\
120 & 7 & 3413.0 & 1191.2 & 7.3 & $<0.01$ \\
200 & 7 & 8339.0 & & & \\
\hline
\end{tabular}



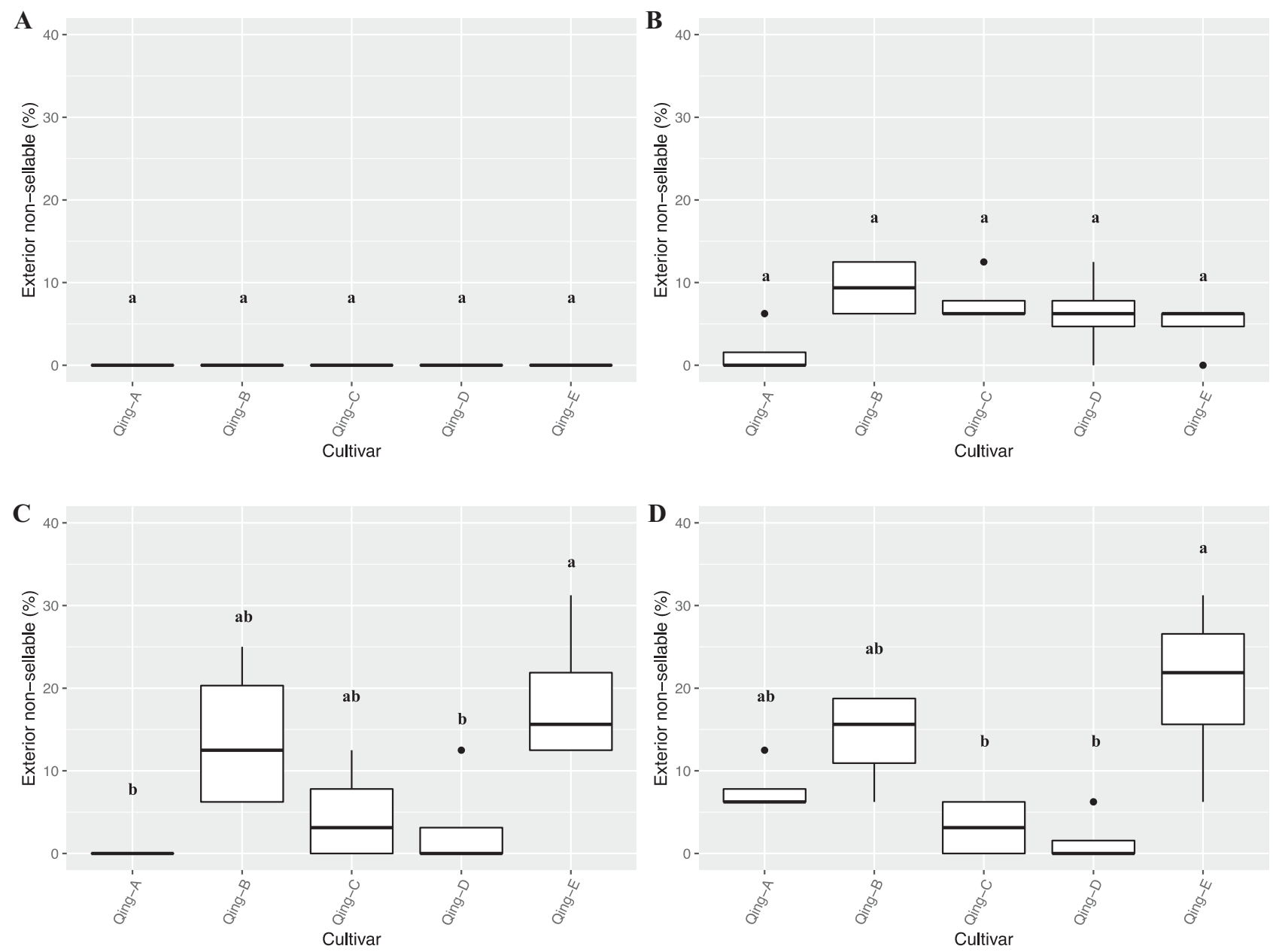

Fig. 4. Percentage of nonsellable 'Qing' chestnuts based on exterior spoilage at (A) $0 \mathrm{~d}$, (B) $60 \mathrm{~d}$, (C) $120 \mathrm{~d}$, and (D) $200 \mathrm{~d}$ postharvest: Qing-A = high-chlorine solution (500 ppm); Qing-B = low-chlorine solution (100 ppm); Qing-C = highhydrogen peroxide (PAA) solution (200 ppm); Qing-D = low-PAA solution (100 ppm); Qing-E = water control. Values followed by different letters are significantly different according to Tukey's honestly significant different $(\alpha=0.05)$ test. $1 \mathrm{ppm}=0.001 \mathrm{~g} \cdot \mathrm{L}^{-1}$.

minimized (Hunt et al., 2012). During a 2004 marketing survey, $68 \%$ of growers declared nut quality as the most important competitive advantage when marketing their nuts (Gold et al., 2006). Many growers planning orchards want to maximize their flexibility in an increasingly competitive production market by storing chestnuts to sell later in the year while still offering a high-quality product. The findings of this study suggest that 'Qing', 'Mossbarger', and, to some extent, 'Peach' and 'Gideon' appear to be less susceptible (up to $200 \mathrm{~d}$ in cold storage) to extreme spoilage on the interior and exterior. 'Qing', 'Mossbarger', 'Peach', and 'Gideon' also have excellent flavor, nut characteristics, and are consistently highyielding (Revord et al., 2021). It would be best to sell 'AU Homestead' and 'Sleeping Giant' within
$120 \mathrm{~d}$ of harvest, whereas it would be best to sell 'Kohr' and 'Hong Kong' within $60 \mathrm{~d}$ of harvest to minimize the loss of nuts caused by postharvest spoilage under the storage conditions used in this experiment.

\section{Prestorage treatment study}

On day 0 , exterior spoilage was not detectable on the 'Qing' nuts with any postharvest treatment (Fig. 4). Like the cultivar evaluation, minor interior spoilage $(<10 \%$ average $)$ was recorded for all five treatments. However, these differences were not statistically significant. At $60 \mathrm{~d}$ under cold storage, there was minor spoilage $(<10 \%$ average $)$ for the treatment groups and control group on both the interior and exterior, with no statistical significance (Table 3 ).
At $120 \mathrm{~d}$, on the exterior, the high chlorine and the low PAA treatment groups showed a significantly lower percentage of nonsellable nuts than the control group, with no difference from the other treatment groups. At $200 \mathrm{~d}$, on the exterior, both the high and low PAA treatment groups showed significantly lower percentages of nonsellable nuts compared with the control group, but there was no difference from the other treatment groups (Fig. 4). There was no difference in the amount of interior spoilage among any treatment groups or compared with the control group throughout the experiment.

The chestnut postharvest treatments evaluated during this study did not show any significant reduction in the percentage of nonsellable 'Qing' nuts compared with the control between 0 and $60 \mathrm{~d}$ in storage. If 
Table 3. Results of the one-way analysis of variance of the percentage of nonsellable chestnuts based on exterior and interior spoilage ratings using the response variable "prestorage treatment" at each evaluation timepoint postharvest.

\begin{tabular}{|c|c|c|c|c|c|}
\hline Time after storage $(\mathrm{d})$ & df & Sum of squares & Mean square & $F$ & $P>F$ \\
\hline \multicolumn{6}{|l|}{ Exterior rating } \\
\hline 0 & 4 & 0 & 0 & $\mathrm{~N} / \mathrm{A}^{\mathrm{z}}$ & $\mathrm{N} / \mathrm{A}$ \\
\hline 60 & 4 & 144.5 & 36.1 & 2.6 & 0.07 \\
\hline 120 & 4 & 1003.9 & 250.9 & 5.2 & $<0.01$ \\
\hline 200 & 4 & 976.6 & 244.1 & 6.6 & $<0.01$ \\
\hline \multicolumn{6}{|l|}{ Interior rating } \\
\hline 120 & 4 & 418.0 & 104.5 & 1.6 & 0.21 \\
\hline 200 & 4 & 125.0 & 31.2 & 0.3 & 0.83 \\
\hline
\end{tabular}

${ }^{\mathrm{z}}$ Not applicable.

'Qing' nuts are to be sold within $60 \mathrm{~d}$ of harvest, then evidence indicates that with proper storage conditions, there may not be any benefit from prestorage chemical treatments. 'Qing' nuts stored for a longer period (120 d or up to $200 \mathrm{~d}$ ) with the high concentration of chlorine or with either the high or low concentration of PAA may have a reduced percentage of nonsellable nuts based on exterior ratings. Prestorage treatment did not show any efficacy for reducing the percentage of nuts with interior spoilage.

Interior spoilage started before storage began (Fig. 3) even after prestorage treatment, which may indicate that certain postharvest pests and pathogens enter the nuts before or after pollination, while the nuts are still in the field, or while the nuts are being harvested. Some nut quality defects such as blossom end rot (Colletotrichum gloeosporiodes), internal kernel breakdown, and chestnut weevil larvae (Curculio sp.) have been shown to enter the nut in the field or during harvesting (Mencarelli, 2001). Some nuts with obvious defects can be removed during sorting and size grading before storage. Still, this preliminary study has demonstrated that internal spoilage may exist in the absence of outer defects and can go undetected until consumption. It is vital to harvest nuts with care to avoid exterior damage to produce highquality chestnuts.

\section{Conclusions}

This study provides preliminary evidence of the differential responses among chestnut cultivars with regard to postharvest quality under the cold storage conditions presented here.
The cultivars Qing, Mossbarger, Peach, Gideon, AU Homestead, and Sleeping Giant seem to offer a degree of longevity under cold storage, whereas Hong Kong and Kohr are not as well-suited for long-term storage because of internal spoilage. Chlorine and PAA prestorage treatments seem to offer some protection against external spoilage, but they do not show any efficacy for protecting against internal spoilage under the storage conditions evaluated here. Future studies are necessary to validate the postharvest spoilage characteristics of cultivars over seasons and locations and to establish best practices with regard to postharvest chemical treatments.

\section{Literature cited}

Aguilar, F.X., M.M. Cernusca, and M.A. Gold. 2009. Exploratory assessment of consumer preferences for chestnut attributes in Missouri. HortTechnology 19(1):216-223, https://doi.org/10.21273/HORTSCI. 19.1.216.

Cai, Z. and M. Gold. 2021. 2021 Annual chestnut market survey report: Price remains high and imports have decreased. Chestnut Grower 23(3):1,4-6.

Cecchini, M., M. Contini, R. Massantini, D. Monarca, and R. Moscetti. 2011. Effects of controlled atmospheres and low temperature on storability of chestnuts manually and mechanically harvested. Postharvest Biol. Technol. 61(2-3):131-136, https://doi.org/10.1016/j.postharvbio. 2011.03 .001 .

Delgado, T., J.A. Pereira, E. Ramalhosa, and S. Casal. 2017. Osmotic dehydration effects on major and minor components of chestnut (Castanea sativa Mill.) slices. J. Food Sci. Technol. 54(9):2694-2703, https://doi. org/10.1007/s13197-017-2706-5.
Delgado, T., J.A. Pereira, E. Ramalhosa, and S. Casal. 2016. Effect of hot air convective drying on the fatty acid and vitamin E composition of chestnut (Castanea sativa Mill.) slices. Eur. Food Res. Technol. 242(8):1299-1306, https://doi. org/10.1007/s00217-015-2633-5.

Donis-González, I.R., D.E. Guyer, and D.W. Fulbright. 2016. Quantification and identification of microorganisms found on shell and kernel of fresh edible chestnuts in Michigan. J. Sci. Food Agr. 96(13):4514-4522, https://doi.org/10. $1002 /$ jsfa.7667.

Ekman, J. 2014. Improved postharvest management of chestnuts. Hort. Innov. Australia Proj. No. CHl3005. 3 Mar. 2021. <https://www.horticulture.com.au/ globalassets/laserfiche/assets/project-reports/ ch13005/chl3005-final-report.pdf>.

Ertan, E., E. Erdal, G. Alkan, and B.E. Algül. 2015. Effects of different postharvest storage methods on the quality parameters of chestnuts (Castanea sativa Mill.). HortScience 50(4):577-581, https://doi. org/10.21273/HORTSCI.50.4.577.

Gold, M.A., M.M. Cernusca, and L.D. Godsey. 2006. Competitive market analysis: Chestnut producers. HortTechnology 16(2):360-369, https://doi.org/ 10.21273/HORTTECH.16.2.0360.

Hochmuth, R.C., R.D. Wallace, P.J.V. Blokland, and J.G. Williamson. 2018. Production and marketing of chestnuts in the southeastern United States. Univ. Florida, IFAS, HS1155. 3 Mar. 2021. < https://edis.ifas.ufl.edu/pdf/HS/ HS115500.pdf $>$.

Hunt, K., M. Gold, W. Reid, and M. Warmund. 2012. Growing chinese chestnuts in Missouri. Univ. Missouri Ctr. Agroforestry, Agroforestry in Action. AF1007-2009.

Hunt, K., M. Gold, W. Reid, and M. Warmund. 2009. Growing chinese chestnuts in Missouri. Univ. Missouri Ctr, Agroforestry AF1007-2012. 
Hunt, K.L., M.A. Gold, and M.R. Warmund. 2005. Chinese chestnut cultivar performance in Missouri. Acta Hort. 693: 145-148, https://doi.org/10.17660/Acta Hortic.2005.693.15.

Kader, A.A. 2003. Chestnut: Recommendations for maintaining postharvest quality. 3 Mar. 2021. <http://postharvest.ucdavis. edu/Commodity_Resources/Fact_Sheets/ Datastores/Fruit_English/?uid=1 $8 \& d s=$ $798>$.

Lione, G., R. Danti, P. Fernandez-Conradi, J.V. Ferreira-Cardoso, F. Lefort, G. Marques, J.B. Meyer, S. Prospero, L. Radócz, C. Robin, T. Turchetti, A.M. Vettraino, and P. Gonthier. 2019. The emerging pathogen of chestnut Gnomoniopsis castaneae: The challenge posed by a versatile fungus. Eur. J. Plant Pathol. 153:671-685, https://doi.org/10.1007/ s10658-018-1597-2.

Mencarelli, F. 2001. Integrated pest management and storage of chestnuts in XinXian County, Henan Province, China. FAO Working project TCP/CPR/8925. 3 Mar. 2021. <http://www.fao.org/3/ ac645e/ac645e00.htm>.
Mendiburu, F. and M. Yaseen. 2020. agricolae: Statistical procedures for agricultural research. R package version 1.4.0. 4 May 2021. <https://myaseen208.github.io/ agricolae $/>$.

R Core Team. 2020. R: A language and environment for statistical computing. $\mathrm{R}$ Foundation for Statistical Computing, Vienna, Austria.

R Studio Team. 2020. RStudio: Integrated development for R. RStudio, Boston, MA.

Revord, R.S., J.M. Nave, G. Miller, N. Meier, J.B. Webber, M.A. Gold, and T. Wahl. 2021. Descriptions of chestnut cultivars for nut production in the eastern and midwestern U.S. HortScience 56(11): 1315-1324, https://doi.org/10.21273/ HORTSCI16090-21.

Ruocco, M., S. Lanzuise, N. Lombardi, R. Varlese, A. Aliberti, S. Carpenito, S.L. Woo, F. Scala, and M. Lorito. 2016. New tools to improve the shelf life of chestnut fruit during storage. Acta Hort. 1144:309-316, https://doi.org/10.17660/ActaHortic. 2016.1144.46.
Tamietti, G. 2016. On the fungal species Gnomoniopsis castaneae ("castanea") and its synonym $G$. smithogilvyi. J. Plant Pathol. 98(2):189-190, https://doi.org/ 10.4454/JPP.V98I2.001.

Vettraino, A.M., V. Vinciguerra, G. Pacini, R. Forniti, V. Goffi, and R. Botondi. 2020. Gaseous ozone as a suitable solution for postharvest chestnut storage: Evaluation of quality parameter trends. Food Bioprocess Technol. 13: 187-193, https://doi.org/10.1007/s11 947-019-02378-9.

Visentin, I., S. Gentile, D. Valentino, P. Gonthier, G. Tamietti, and F. Cardinale. 2012. Gnomoniopsis castanea sp. nov (Gnomoniaceae, Diaporthales) as the causal agent of nut rot in sweet chestnut. J. Plant Pathol. 94(2):411-419, https:// doi.org/10.4454/JPP.FA.2012.045.

U.S. Department of Agriculture, National Agriculture Statistics Service. 2018. Noncitrus fruits and nuts June 2017 summary. 20 Mar. 2021. <https://www.nass.usda. gov/Publications/Todays_Reports/ reports/ncit0618.pdf $>$. 